\title{
Fiscaoeconomia
}

E-ISSN: 2564-7504

2021, Volume 5, Issue 2, 372-389

https://dergipark.org.tr/tr/pub/fsecon

\section{Firmalar ve Dünya Ekonomisi}

Firms and the World Economy

\section{Şiir ERKÖK YILMAZ ${ }^{1}$}

\section{Öz}

Firmaların kâr maksimizasyonu amacıyla aldıkları kararlar ve denedikleri yöntemler onların örgüt yapılarını ve nereye nasıl yatırım yapacaklarını etkilemekle kalmamış, dünya ekonomisinin de bu doğrultuda biçimlenmesine yol açmıştır. Son yıllarda taşımacılık ve bilişim teknolojilerinde yaşanan gelişmeler ve özellikle 80'li yıllardan itibaren ticaretin ve sermaye akımlarının liberalizasyonuna yönelik uygulamalar ulus aşırı üretimi firmalar için avantajlı hale getirmiştir. Üretimin farklı aşamalarını değişik coğrafyalara dağıtan firmalar hem girdi maliyetlerini ucuzlatmış hem de ölçek ekonomilerinden yararlanmışlardır. Değer zincirleri adı altında organize edilen bu parçalanma süreci üretimin ve ticaretin boyutlarının genişlemesine ve yeni ülkelerin dünya ekonomisine eklemlenmesine yol açmıştır. Hiper globalizasyon diye anılan bu çağda dünya ekonomisine yön veren büyük firmalardır. Ulus Aşırı Şirketler veya süperstar şirketler diye adlandırılan bu firmaların piyasa gücü soyut varlıklardan oluşmaktadır ve bu gücü sürdürebilmenin yolu $A R-G E$ çalışmalarından geçmektedir. AR-GE çalışmalarında bulunan her firma radikal bir yeniliğe imza atacak değildir ancak büyük firmaların AR-GE'yi ticarileştirmek açısından üstünlükleri vardır. Bu nedenle gerekirse devlet eliyle büyük firmalar oluşturmak ve AR-GE yatırımlarına öncülük etmek gelişmekte olan ülkeler açısından son derece önemlidir. Değer zincirleri doğrultusunda yapılan küresel üretim ve ticaretin bölgeler arası yakınsama sağladığı yolunda görüşler ileri sürülmektedir. Gelişmiş ve gelişmekte olan bölge ekonomileri (Kuzey ve Güney) arasında bir yakınsamadan söz etmek güçtür. Yakınsama Çin ile gelişmiş ülkeler arasındadır ve Çin bu başarısını neo liberal politikalar izlemek yerine bu politikalardan sakınmasına borçludur. Yüksek endüstriyel kalkınma bölgeleri, kamusal ulus aşırı şirketler gibi uygulamalarla ileri teknolojinin transferini ve kendi ülkesinde geliştirilmesini sağlamıştır. Gelişmekte Olan Ülkeler teknolojideki beklenmedik ve sert dönüşümlere hazır olmak zorundadır. Yeni teknolojilerin sunacağı fırsatlardan yararlanmak ancak devlet desteğini arkasında hisseden büyük firmaların sahip oldukları beşeri sermaye ile mümkün olacaktır.

Jel Kodları: F23, F50, F60

Anahtar Kelimeler: Ulus Aşırı Şirketler, Dünya Ekonomisi, Küreselleşme

\footnotetext{
${ }^{1}$ Prof. Dr., Emekli Öğretim Üyesi, Gazi Üniversitesi iỉBF îktisat Bölümü, siirerkok@gmail.com, ORCID: 00000001-7790-6415
}

Citation/Atıf: Erkök Yılmaz, Ş. (2021). Firmalar ve dünya ekonomisi. Fiscaoeconomia, 5(2), 372-389. doi: $10.25295 /$ fsecon.916030 
Erkök Yılmaz, Ş. (2021). Firmalar ve dünya ekonomisi.

Fiscaoeconomia, 5(2), 372-389. doi: 10.25295/fsecon.916030

\begin{abstract}
Ronald Coase in 1930s observed that firms grew only so long as it was cheaper for them to complete additional parts of the production process in-house. From 1980 onwards trade and financial liberalization accompanied by radical technological developments in transportation, information and communication (IC) have reduced the cost of cross-border trade. Firms through global value chains (GVC) unbundled their production processes thus changed the geography of jobs and traditional trade patterns. Nowadays large firms named Transnational Corporations (TNC) or superstar firms dominate the international production through global value chains. The aim and organization of these chains determine the hierarchy among the firms. Firms' market power is the outcome of the intangibles that specially belong to the lead firm in GVC. These intangible assets are not easily obtained but derive huge profits. In order to catch and sustain a competitive advantage firms ought to increase these intangible assets through R\&D investments. Recent decades are called as hyper globalization era and the characteristic feature of this era is the hyper competition among large firms through innovation. Large firms are luckier to carry on R\&D activities and to evaluate and commercialize any kind of invention or innovation wherever it has been developed. Large firms are getting larger by means of ICT and are the dominants of the global economy. GVC trade and facilities that ICT bring to the emerging countries help them to join in international production and to attain higher rates of growth but it is hard to mention about a convergence between the developing and the developed economies. Only the countries which succeeded in transferring the core R\&D activities to their territories and upgrading the production processes under their responsibility are ranked among the top economies that monitor the global economy. Despite the neoliberal recipes designed for the emerging economies, state intervention is frequently taken place in the developed South (especially in China) where State Owned Enterprises and Sovereign Wealth Funds emerged as new kind of investors. Especially Chinese State-Owned Enterprises ranked among the world's top R\&D investors. In emerging economies governments should adopt a strategic policy to support effectively the firms that are rich in human capital and are able to undertake counter measures against surprising attacks of the digital technology.
\end{abstract}

Jel Codes: F23, F50, F60

Keywords: Transnational Corporations, World Economy, Globalization

\title{
1. Giriş
}

Firmalar ders kitaplarında anlatıldığı gibi veri fiyatlar karşısında kâr maksimizasyonu yapan soyut birimler değildir. Üretebilmek için girdiler satın alan ve bu girdileri en etkin bir biçimde üretime katan bu nedenle de sürekli diğer firmalar ile alışveriş içinde olan, yalnızca kâr etmek değil ayrıca piyasada kalma mücadelesi veren organizmalardır. Mikro ekonomi ders kitapları firmaların bu girdileri piyasadan satın aldığı ve satın alma dışında bir başka seçeneklerinin bulunmadığı varsayımı altında yazı ımıştır. Oysa girdiler sayıca artmış, çeşit ve nitelik olarak farklılaşmış ve firmaların girdi fiyatları dışında diğer firmalarla işbirliği içinde olma zorunluluğu belirmiştir. İşte bu zorunluluk firmaları yeni örgütlenme modelleri geliştirmeye ve sürekli yeni üretim ilişkileri kurmaya itmektedir. 
Erkök Yılmaz, Ş. (2021). Firmalar ve dünya ekonomisi.

Fiscaoeconomia, 5(2), 372-389. doi: 10.25295/fsecon.916030

\section{Firmaların Örgütlenme Modeli ve Uluslararası Üretim}

Firmaların üretim yapabilmek dışardan satın aldıkları girdilerin maliyeti arttıkça firma R. Coase (1937)'ın da belirttiği gibi üretim için gerekli satın alma işlemlerine son verip aynı işlemleri kendi bünyesi içinde toparlamaya başlamaktadır. Firmanın büyüme sürecine etki eden en önemli faktör onun başka firmalardan satın aldıklarını kendi içinde yapmaya başlamasıdır. Firma için üretimin içselleştirilmesi olarak tanımlanan bu olay firmanın büyümesini de beraberinde getirir. Bir başka deyişle piyasadan silinmemek ve daha çok kâr elde edebilmek için maliyetleri düşürmenin bir yolu üretimin içselleştirilmesidir bu da beraberinde büyümeyi getirir. Dikey bütünleşme olarak da anılan bu gelişmenin bir maliyeti vardır. Dikey işbölümü artıkça şirketlerin çapı genişlemekte ve şirket yönetiminde yeni bir yapılanmaya gidilmesi zorunlu hale gelmektedir.

S.Hymer (1968) şirket yapısı ile uluslararası işbölümü arasında bir paralellik kurmaktadır. Hymer görüşlerini Chandler-Redlich'in örgüt şemasına dayandırmıştır. Şirketler üç düzeyde örgütlenmekte, en alttaki üçüncü düzeyde günlük işlemler yer almaktadır. İkinci düzey üçüncü düzeyde çalışanları koordine etmektedir. Birinci düzey ise en üst düzey yöneticilerinin yer aldığı, stratejik ve taktik geliştirmekle yükümlü olanların bulunduğu düzeydir. Hymer'e göre bu yapılanma uluslararası düzeyde kendini tekrar etmekte ve birinci düzey etkinliklerin toplandığı ülke veya bölgeler diğerlerine hükmetmektedir. Bir başka deyişle dünya ekonomisi aynen firma içinde yaşandığı gibi hiyerarşik bir yapılanma içerisindedir. Hymer bu görüşlerini çok uluslu şirket modelinden hareketle oluşturmuştur.

Dünya ekonomisini tek bir üretim sistemi olarak ele alan I.Wallerstein (1982) ise kapitalist üretim sistemini çevrede yaratılan artık değerin Merkeze transferi olarak algıladığından ülkelerin Merkez- Yarı-çevre ve Çevre olarak hiyerarşik bir dizilim içinde olduklarına ve Merkezin gücünün teknolojik üstünlükten kaynaklandığına vurgu yapmaktadır. Merkez ülke, askeri ve siyasi gücü elinde bulundurarak hegemonyasını sürdürmeye çalışmaktadır. Wallerstein firma temelinden hareket etmese de ülkeler arasındaki hiyerarşik yapılanmaya dikkatleri çekmektedir. Her iki yaklaşımda da kâr ve potansiyel kârı (artık değer) artırmak için başvurulan yöntemler hiyerarşik yapılanmaya yol açmaktadır. Bu nedenle J.Dunning (1995) bu yapıyı hiyerarşik kapitalizm olarak adlandırmıştır.

Üretim için gerekli temel girdilerin üretimini ve diğer yan üretim süreçlerini bir arada toplamak sanıldığı gibi maliyetten tasarrufa yol açmayabilir. O zaman yapılacak olan bu işlemleri firmalar arası sözleşmeler yaparak piyasadan tedarik etmektir. Firmalar arası ortaklıklar, firma birleşmeleri Dunning'e göre bu amaçla yapılmaktadır. Bu ortaklıklar ülke içindeki yerli firmalarla kurulabileceği gibi yabancı ülkelerdeki firmalarla da gerçekleştirilebilir. Dunning'e göre tek bir firma açısından bakıldığında içselleşme karşıtı bir gelişme gibi görünse de ortaklık veya aynı üretim ağı içindeki firmalar açısından bu sözleşmeler girdilerde içselleştirme sürecinin firmalar arasında sürmesi anlamına gelmektedir. 1980 sonrası ticaretin ve özellikle 1990'larda sermayenin liberalizasyonu bu sözleşmelerin yabancı firmalarla imzalanmasını daha avantajı hale getirmiştir. Dış Kaynaklanma olarak adlandırdığımız bu yöntem firmaları dikey bütünleşme yerine sınır aşırı üretime yöneltmiştir. Dunning dünya kapitalizminin vardığı bu aşamayı Anlaşmalı Kapitalizm olarak adlandırmaktadır. Dunning anlaşmalı kapitalizmi "birbiriyle ilintili üretim etkinliklerinin müştereken içselleştirilmesi" olarak tanımlamaktadır (Dunning, 1995:464). Bu anlaşmaların maliyet avantajının dışında da firmalara sağladığı 
Erkök Yılmaz, Ş. (2021). Firmalar ve dünya ekonomisi.

Fiscaoeconomia, 5(2), 372-389. doi: 10.25295/fsecon.916030

birtakım kolaylıklar vardır. Örneğin firmalar kendilerinde olmayan bir takım özel varlıkları bu yolla edinebilir. Dunning buna "varlık arayışı içinde ortaklık davranışı" demektedir. Firmalar arası ortaklık anlaşmalarının bir diğer yaygın amacı da piyasayı genişleterek büyük ölçekte üretim yapılmasını sağlamaktır. Dunning bu avantajı "piyasa duruşlu sözleşme davranışı" olarak tanımlamaktadır (Dunning,1995:465-67). Anlaşmalı kapitalizmde firmalar arasında rekabet yerini tamamlayıcılık ilişkisine bırakmıştır. Üretim firmalar arasındaki sözleşme çerçevesinde yürütülmektedir. Sözleşmeye taraf olan katılımcıların ortak amacı üretim zincirindeki yerlerinde en yüksek katma değeri yaratmaktır. Üretim ve yan hizmetler birbirinden kopuk değildir. Denetim, üretimin her aşamasında yapılmaktadır. Bir başka deyişle anlaşmalı kapitalizmde üretim süreci hiyerarşik bir yapı göstermemektedir. Ancak Dunning'in sözünü ettiği anlaşmalı kapitalizmde firmaların asıl amacının gerekli girdileri ucuza elde etmekten çok sözleşme yaptıkları firmaya özgü özel varlıkları ele geçirmek olduğu unutulmamalıdır. Bilginin değer katan en önemli varlık olması ve sözleşme yapılan firmanın sahip olduğu bilgi ve beşeri sermaye anlaşmalı kapitalizmde firma davranışını belirleyen en önemli etmendir. Son yıllarda doğrudan yatırım yapmak yerine mevcut şirketlerle kaynaşma veya satın alma stratejisinin benimsenmesinin altında da bu gerekçe yatmaktadır. (Dunning, 1998:52-54). Anlaşmalı kapitalizmin hiyerarşik bir yapı içinde olmaması da anlaşan firmaların kendine özgü piyasa güçlerine sahip olmalarıdır.

Çağımızda firmaların gücünü belirleyen dağarcıklarındaki soyut varlıklardır. Bu soyut varlıklar başta patentler olmak üzere markalar, coğrafi işaretler, telif hakları, ticari sırlar, tasarım, yazıım, pazar araştırması, örgütlenme modelleri, veriler gibi firmanın rakipleri açısından çok değerli olan bilgilerdir. Son yıllarda firmalar ulus aşırı üretimlerini ellerinde bulundurdukları bu soyut varlıkları kullanarak yapmaktadırlar.

Bilgi ve iletişim teknolojilerinde yaşanan hız ve ucuzluk üretimin kolayca bir mekandan diğerine hiçbir kalite farkı yaşanmadan kaydırılmasını, yeni üretim merkezlerinin çabucak kurulup devreye girmesini sağlayabilmektedir. Üretim, lisanslama veya irili ufaklı firmalarla imzalanan imalat sözleşmeleri ile değer zincirleri oluşturularak gerçekleştirilmekte, sermaye veya emeğin yabancı bir ülkeye göç etmesine gerek kalmamaktadır. Doğrudan yatırım verileri yatay bir seyir izlerken hizmetler ve soyut varlıklara yapılan ödemeler (royalty, lisanslama bedelleri vs.) hızlı bir artış göstermektedir. En tepede yer alan 100 ulus aşırı şirket (UAŞ) dış ülkelere yaptığı satışı artırırken dış varlıklarında veya yabancı eleman kullanımında aynı oranda artış yaşanmamıştır (UNCTAD-WIR, 2019:7). Bu da göstermektedir ki UAŞ'ler son yıllarda yatırım yapma zahmetine katlanmaksızın hafif işlemlerle yabancı piyasalara girmektedir (UNCTAD-WIR, 2019:7). Uluslararası ticaretin büyük bir bölümü artık global değer zincirlerine eklemlenmiş ülkeler arasında ve girdi ticareti olarak yapılmaktadır. Değer zincirlerinde yer alan firmalar arasında üretime kattıkları değer ölçüsünde bir hiyerarşi bulunmaktadır.

Şirketler arası hiyerarşi ve bilgi akışının yönünü belirleyen ilişkiler Global Değer Zincirlerinin türlerine, üretilen ürünlerin karmaşıklığına, işlemlerin sınıflandırılabilirliğine ve tedarikçi firmaların yapabilirliklerine göre değişmektedir (WBG-WDR, 2020:32). Baldwin (2012) değer zincirlerini yılan ve örümcek olarak iki kategoride toplamaktadır. "Yılan" a benzetilen değer zincirlerinde üretim aşamaları birbirini izleyecek biçimde sıralanmıştır. Her bir aşama, bir önceki üretim değerinin üzerine bir değer katmaktadır. Katma değer açısından aşamalar arasında çok büyük farklar söz konusu değildir. "Örümcek"e benzetilen değer zincirlerinde ise 
Erkök Yılmaz, Ş. (2021). Firmalar ve dünya ekonomisi.

Fiscaoeconomia, 5(2), 372-389. doi: 10.25295/fsecon.916030

çevrede üretilen parçaların ağın merkezinde bir araya gelmesi gerekmektedir. Ağın çeşitli noktalarında üretilen parçalar merkezde bir araya getirildiğinde bir değer kazanırlar bu nedenle çevre işlemlerdeki katma değer ile merkezdeki katma değer farklıdır. Merkez ile çevre arasında yaratılan katma değer açısından hiyerarşik bir durum söz konusudur. Bu durum firmalar arası ilişkinin de belirleyicisidir.

Gereffi, Memedoviç, (2003) global değer zincirlerini üretici yönetimli ve alıcı yönetimli olarak sınıflandırmıştır. Üretici yönetimli zincirler "örümcek" benzetmesiyle uyumludur. Ağırlıklı olarak teknoloji ve AR-GE çalışmalarıyla öne çıkan bu zincirlerde Merkez, şubeleriyle teknolojik bilgiyi paylaşmaz ve firmalar arasında hiyerarşik bir ilişki yaşanır. Elektronik, otomotiv, uzay ve eczacılık alanındaki değer zincirleri bu tür örgütlenmenin tipik örnekleridir. Apple, GM, Samsung, Sony, Toyota üretici yönetimli değer zincirlerine örnek olarak gösterilebilir. Buna karşılık alıcı yönetimli değer zincirleri "yılan" benzetmesine daha yakındır. Birden çok üretici birbirini tamamlar biçimde çalışır, zincire önderlik eden firma genelde ürünün pazarlanması ve satışından sorumludur. Tekstil ve giyim sanayileri alıcı yönetimli değer zincirlerine örnek olarak gösterilir. Walmart, JC Penny ve Nike gibi şirketleri bu bağlamda sayabiliriz (WBG-WDR, 2020:33-34). Firmalar arası hiyerarşik ilişkinin temelinde AR-GE çalışmaları yatmaktadır. Genellikle UAŞ'ler AR-GE gibi yüksek katma değer yaratan üretim faaliyetlerini şirket merkezinin yakınında bulundurmaya özen gösterirler. Bu nedenle Hymer'in sözünü ettiği Eşitsiz Gelişme Yasasının firma ölçeğinin büyümesi yasasının uluslararası türevi olduğu ileri sürülmüştür. Gelişmekte olan ülkeler için UAŞ'nin merkez faaliyetlerine ev sahipliği yapmak küresel ticarette kalıcı ve bağımsız bir rol üstlenmenin vazgeçilmez koşuludur (Kazcmarczyk, 2019:11).

Küresel boyuta taşınan üretim ve ticaret ilişkileri nedeniyle içinde bulunduğumuz bu çağa Hiper globalizasyon çağı denilmektedir. Hiper globalizasyon çağında firmaların hiper rekabetçi bir ortamda çalıştıklarına vurgu yapılmaktadır. D’Aveni(1994) hiper rekabeti şöyle tanımlamaktadır: Piyasada rekabet kurallarının hızla değiştiği ve firmaların rakiplerini alt edebilmek için çarçabuk yeni üstünlükler elde etmelerini gerektiren bir ortam. (aktaran Brynjolfsson vd, 2012:3). Hiper rekabet ortamında çeşitli küresel oyuncu ve hızlı teknolojik değişiklikler yüzünden piyasalar eskisinden çok daha istikrarsız ve çok daha belirsizliklerle doludur. Ancak teknolojik atılım yapabilen bir firma hızla büyüyebilir, tüm sektöre egemen olabilir hatta yeni iş alanları açabilir ne var ki firmanın ele geçirdiği bu üstünlük geçicidir. Tıpkı Schumpeter'in yaratıcı yıkım tezinde ileri sürüldüğü gibi bu üstünlük firmaya bir tür tekelci güç sağlar ve bu üstünlüğün firmaya olan getirisi son derece yüksektir. Gücü eline geçiren firma sektördeki kazancın tümünü almaktadır. Yenilerin piyasaya girmesiyle veya daha üstün bir ürün geliştirmeleriyle birlikte firma bu gücünü yitirir hatta temelli piyasadan silinebilir. 0 nedenle hiper rekabet ortamında piyasalarda kargaşa ile yoğunlaşma bir arada görülür. Bilişim teknolojileri en başarılı uygulamaların diğer firmalarca kopyalanmasına ve tekrar edilmesine olanak sağlayarak rekabetçi gücün hızıca el değiştirmesine yol açmaktadır. Bilişim teknolojilerinin bir diğer sonucu da firmaların çok az eleman, çok az sermaye malı ile pekala büyük ölçekte (Scale Without Mass) iş görebilme yetisini kazanmış olmalarıdır. Bu anılan ortamda gücünü elindeki soyut varlıklara borçlu olduğunu bilen her firma soyut varlıkları artırmak üzere sürekli yenilik yapmak, AR-GE çalışmalarını sürdürmek; gerekirse AR-GE açısından diğer firmalarla işbirliğini geliştirmek zorundadır. Firmanın piyasadaki rekabetçi gücü geçici bir güçtür ve bunun sürdürülebilir olması AR-GE çalışmalarından geçmektedir. Bu 
Erkök Yılmaz, Ş. (2021). Firmalar ve dünya ekonomisi.

Fiscaoeconomia, 5(2), 372-389. doi: 10.25295/fsecon.916030

yüzden hiper globalleşme çağı AR-GE yarışlarının da yaşandığı bir çağdır. AR-GE çalışmaları, yeni mal ve hizmetlerin ortaya çıkmasına yol açarak ticaret hacminin genişlemesini sağlamıştır. 2017 yılında ticaretin \%65'i 1992 yılında varlığı bile söz konusu olmayan mallar üzerinden yapılmıştır (WBG-WDR, 2020:4).

\section{AR-GE Yatırımları ve Büyük Firmalar}

AR-GE'ye yapılan her yatırım yeniliğe, özellikle de radikal bir yeniliğe imza atacak, diye bir kural yoktur. Her büyük firma yenilik yapar, diye de bir kural yoktur. Tam tersine yenilikler küçük, hatta piyasa deneyimi olmayan bir firmadan da çıkabilir. Ancak elinin altında AR-GE laboratuvarı bulunan, bilgili teknik elemanları bünyesinde barındıran bir firma yeniliğin değerini ânında kavrayabilir, o yeniliği özümseyebilir ve geliştirebilir. Rekabetçilik açısından da önemli olan budur. Sermaye bakımından sorun yaşamayan, satış ağı güçlü firmalar dünyanın herhangi bir köşesinde geliştirilmiş bir yeniliği satın alıp üretimini kolaylıkla gerçekleştirebilirler. AR-GE'nin ülke ve bölge bazında son derece yoğunlaşmış olmasını bu nedenle büyük firmaların coğrafi dağılımı ile ilişkilendirmek yanlış olmaz. Bir milyar avro üstünde AR-GE yatırımı yapan 159 şirket vardır. Bu şirketlerin 58'i ABD, 41'i AB, 26'sı Japonya, 19'u Çin, 5'er tanesi G. Kore ve İsviçre, 3'ü Tayvan ve 1'er tanesi İsrail ve Hindistan'da yer almaktadır. Böylece en yüksek AR-GE yatırımı yapan şirketlerin bulunduğu $A B D$, Çin ve Japonya toplam AR-GE yatırımlarının \%63'ünü, sıradaki on ülke $\% 77$ 'sini ve tümü toplam AR-GE yatırımlarının \%92'sini üstlenmiş durumdadır. $A B$ içinde Almanya, İngiltere ve Fransa on sekiz $A B$ ülkesindeki toplam AR-GE yatırımlarının \%69'unu barındırmaktadır (JRC-EC,2019:32). ARGE yatırımlarının sektörel dağılımında da çarpıcı bir yoğunlaşma ve bölgeler arası uzmanlaşma dikkat çekmektedir. AR-GE çalışmaları dört sektörde yoğunlaşmıştır: otomotiv, sağlık, bilişim teknolojisi ürünleri ve bilişim teknolojisi hizmetleri. Bu alanlar gelecekte yaşanacak AR-GE yarışlarının ve ürün yeniliklerinin de bu günden habercisidir. Bütün bu gelişmeler hiper globalleşme çağında ulus aşırı şirketlerin pazar paylarını artırma yani kârlılık odaklı büyüme politikalarının uzantısıdır. AR-GE çalışmalarına ilişkin son yıllarda gözlenen bir başka çarpıcı gelişme de çok gizli tutulması gereken alanlarda teknolojik çalışmaların şirket merkezinin yer aldığı ülkede geri kalanının, özellikle tüketici tercihlerinin önemli olduğu ürün yeniliklerde, ürünün satılacağı ülke pazarında geliştirilmesidir. "Tersine yenilik" süreci diye adlandırılan bu durum AR-GE'nin uluslararasılaşmasına örnek olarak gösterilmektedir ( Laperche, Lefebvre, 2012). "Tersine yenilik" firmaların "talep-yönünden ölçek ekonomisi"nden yararlanmalarını göstermek açısından da iyi bir örnektir.

\section{Süperstar Firmalar ve Dijital Platformlar}

Bütün bu gelişmelere karşın yeniliklerin er geç büyük firmaların gücüne güç katacağını söylemek yanlış olmaz. Rekabetçi olabilmek için uluslararası üretime baş vuran ve bu gücünü yeniliklerle sürdüreceğinin bilincinde olan firmalar hem satış gelirlerinin büyüklüğü, hem bu satış gelirlerinin içinde AR-GE'ye ayırdıkları payla (AR-GE yoğunluğu) dünya ekonomisinde söz sahibi oldukları gibi, bütçeleriyle, çalıştırdıkları eleman sayılarıyla dünyanın hatırı sayılır devletleriyle boy ölçüşebilmekte, hatta onların iç ve dış politikalarına yön verebilmektedirler. Bu firmaların bir yandan AR-GE çalışmaları yaparak ekonomik gücü ellerinde tutarken, bir diğer yandan rakip firmaların yenilikçi çalışmalarını engelleyebileceği, AR-GE ve teknolojik ilerleme için bir tehdit oluşturabilecekleri üzerinde de durulmaktadır (Kaczmarczyk, 2018:7). Uluslararası alanda çok sayıda üreticiyle çalışıyor görünseler de dünya üretimine de ticaretine 
Erkök Yılmaz, Ş. (2021). Firmalar ve dünya ekonomisi.

Fiscaoeconomia, 5(2), 372-389. doi: 10.25295/fsecon.916030

de hatta ülkeler ve bölgeler arası servet dağılımına da yön veren onlardır. Ülkelerin açıklanmış karşılaştırmalı üstünlüklerini belirleyen, bu üstünlüklerin değişmesine yol açan da gene bu süperstar firmaların stratejileri, tercihleri ve kararlarıdır. Örneğin Nokia Finlandiya için, Samsung G. Kore için böylesi bir rol üstlenmiştir (Freund, Pierola(2015) aktaran Kaczmarczyk, 2019:2). Gelişmekte olan 32 ülkede yapılan bir çalışma beş büyük ihracatçı firmanın ortalama olarak bir ülke ihracatının 1/3ünü oluşturduğunu, ihracat artışlarının \%50'sini açıkladığını ve ihracatı çeşitlendirmeden kaynaklanan büyümenin $1 / 3^{\prime}$ üne neden olduğunu göstermiştir (WBG-WDR, 2019, s.37)

Dünya ekonomisinin hâkimi büyük firmalardır. Küresel ölçekte iş gören büyük firmaların \%10'u kârların \%80'ini yönlendirmektedir (WBG-WDR 2019:37). Süperstar firmalar (bu kavramı ilk olarak Sherwin Rosen 1981 yılında kullanmıştır) olarak nitelenen bu firmalar dijital teknolojilerden yararlanarak daha da büyümüşlerdir. Dijital teknolojilerden yararlanma becerilerine bağlı olarak firmaların çok daha hızlı büyüdükleri ve piyasa değerlerini artırdıkları yadsınamaz bir olgu olarak karşımızda durmaktadır. Firmalar arası genişleyen uçurum özellikle dijital alanda çalışan firmalar açısından daha da dikkat çekicidir. Piyasa değeri itibariyle en büyük 25 teknik firmanın 14'ü $A B D^{\prime}$ de; 3'ü $A B^{\prime}$ de; 3'ü Çin'de; 4'ü diğer Asya ülkelerinde, 1'i Afrika'da bulunmaktadır. ABD'deki en büyük 3 firmanın ortalama piyasa değeri 400 milyar dolardır. Çin'deki ve $A B^{\prime}$ deki firmalar için bu değerler sırasıyla ortalama 200 ve 69 milyar dolardır (UNCTAD-TDR, 2018:vi).

Dijital teknoloji dev firmalar arasına Dijital platformlar adıyla yeni tür firmaların katılmasına olanak vermiştir. Dijital platformlar dünyanın herhangi bir yerinde farklı markalarla çalışanları bir araya getirmekte ve geniş bir platformda firmalar, satıcılar- alıcılar hatta yenilikçiler arasında iletişimi kolaylaştırmaktadır. Zaman içinde dijital platform çeşitleri artış göstermiştir:

İşlem platformları: Birbirini yüz yüze tanıma olanağı olmayan bireyler arasında etkileşim geliştirmektedir.

Yenilik platformları: Yenilikleri tamamlayıcı hizmet ve ürün geliştirenlerin birbirlerini bulmalarına ve yenilik blokları oluşturmalarına hizmet etmektedir.

Pazar yerleri: Bireyler arasında, işyerleri arasında ve işyerleri ile tüketiciler arasında ilişkileri geliştirmeye yönelik platformlardır. En büyük ve en güçlü Pazar Yerleri ABD’dedir. Çin de bu alanda yol kat etmektedir.

E-ticaret platformları kullanıcılar açısından en büyük olanlarıdır. Ali Baba T Mall (400 milyonÇin dışındaki aboneler hariç), Amazon (304 milyon), eBay (167 milyon-küresel çapta); dört büyük yatırımc finansöründen üçü $A B D^{\prime}$ de (Uber, Airbnb ve Lyft), biri Çin'de bulunmaktadır (DiDi Chuxing). Sosyal Medya ve arama motorlarında $A B D$ üstünlüğünü sürdürmektedir. Internet arama platformlarında ABD firmalarının üstünlüğü vardır, bu alanda Baidu ve Yandex ile Çin ve Rusya Federasyonu rekabet etmeye çalışmaktadır. Mobil cihazlar için ABD üstünlüğü tartışmasızdır: Android (piyasa payı \%81.7), iOS (\%17.9) ve Windows (\%0.3) piyasaya egemendir (UNCTAD-TDR, 2018:78).

Bu platformlar güçlerini veri ticaretinden almaktadır. Firmaya özgü uygulamalar, elemanlar, müşteri bilgileri, kısaca her türlü veri piyasa değeri olduğu sürece firmanın varlığını oluşturmaktadır ve hisse devri, ortaklıklar vs. bu değerlerin üzerinden gerçekleşmektedir. Soyut varlıkların tanımı ve içeriği genişledikçe üstüne üstlük bu varlıklara erişim uluslararası 
Erkök Yılmaz, Ş. (2021). Firmalar ve dünya ekonomisi.

Fiscaoeconomia, 5(2), 372-389. doi: 10.25295/fsecon.916030

sözleşmelerle kısıtlandıkça soyut varlıklar giderek daha çok değer kazanmaktadır. Nitekim küresel düzeyde fikri mülkiyet hakları için yapılan ödemeler 1995 yılında 50 milyar\$ iken bu tutar 2015 yılında 367 milyar\$ olmuştur (UNCTAD-TDR, 2018:55). Büyük firmaların varlıklarının 2/3'ünü bu soyut varlıklar oluşturmaktadır. Platformlara ufak bir bedel karşılığı katılmak mümkündür. Platform sahibi bu sayede para kazanmaktadır. Ancak platformlar asıl gelirlerini veri ticaretinden elde etmektedir. Piyasadan topladıkları verileri, bir başka piyasadaki firmalara -firma etkinliğini artırma bahanesi ile- kullandırmakta ve gelir elde etmektedirler. Verilerin yeniden üretimi, kopyalanması sıfır veya yok denecek kadar düşük bir maliyetle yapılsa da fikri mülkiyet hakları, ölçek avantajı, piyasa gücü ve diğer rekabet-karşıtı uygulamalar ile herkesin kullanımına açık olmaktan çıkarılabilir ve üzerlerinde bir tekel oluşturulabilir. Veri ticareti açısından "talep yönünden ölçek ekonomileri" piyasadaki en büyük firmanın tüketicilere kilitlenmesi ve pazar payını artırmasına şans vermektedir (UNCTAD-TDR, 2018:79). Bu nedenle dijital platformları kontrol eden birkaç firmanın tekelci güç elde etmesini önleyecek tekel-karşıtı önlemlerin geliştirilmesi ve toplanan verilerin bu firmalar tarafından kötüye kullanılmasının önüne geçilmesi zorunludur.

Platformların sayıca çoğalması serbest çalışanların ufak bir bedel karşılığı piyasaya giriş yapabilmesine olanak vermiştir, tüketiciler de bu platformlar aracılığıyla çevrim içi hizmetlerden yararlanmaktadır. Tüketicilerin platformlara duydukları güven platformların başka iş kollarına el atması ve genişlemesi açısından da önemlidir. Platformlar yeni ve esnek çalışmaya olanak tanıyan iş fırsatları yaratarak işgücü arzının genişlemesine, işçilerin çalışma saatlerini kendilerinin belirlemesine, çalışma koşullarında esneklik sağlayarak özellikle kadınların işgücüne katılımlarını artırmada önemli bir işlev görmektedir. Ancak dijital platformlarla birlikte devamlı ve geçici işler arasındaki ayrım giderek belirsizleşmiştir. Mal ve hizmet ticareti arasındaki ayrım için de aynı saptamayı yapmak mümkündür. Platformlar genellikle firmalara parasız hizmet sunmakta, bunun karşılığında elde ettikleri müşteri bilgilerini bir başka piyasada paraya çevirmektedirler. Platformlar bu ve benzeri yollarla çok yüksek kâr elde etmekte ve kârlarını çok kısa bir sürede birkaç katına çıkarmaktadırlar. Örneğin Amazon (ABD) için kâr/satışlar 2005'de \%10 iken 2015'te \%23 olmuştur. Aynı değerler Alibaba (Çin) için 2011'de \%10 iken 2015'te \%32'dir (UNCTAD-TDR,2018:vi). Bu da platformlarla birlikte yeni tekelci eğilimlerin baş göstereceği anlamına gelmekte ve ülkeler rekabet hukukunu yeniden düzenleme gereği ile karşı karşıya kalmaktadırlar (WBG-WDR, 2019, s.4142). Küresel ölçekte iş yapan ve yalnızca bulutta var olan platform firmalarını izlemek, düzenlemek özellikle vergilendirmek ülke devletleri için ciddi bir sorun haline gelmiştir. 2015 yılı itibariyle dünya gelir sıralamasında on şirket İsviçre, Norveç, Rusya Federasyonunu gibi yüksek gelirli ülkeleri geride bırakmıştır. Bunlar, Walmart, State Grid Corporation of China, China National Petroleum, Sinopee Group, Royal Dutch Shell, Exxon Mobile, Volkswagen, Toyota Motor ve BP'dir. Bu şirketlerin ellerindeki parasal güç ile hükümet politikalarını biçimlendirmeleri hatta demokrasiye tehdit oluşturmaları gibi olasılıklar üzerinde durulmaktadır (Bk. Zingales, 2017:113). Ancak her şeye karşın, hiper globalizasyon çağında yazılım teknolojisine egemen küçük üreticiler ve yeni başlayan firmalar için bir umut doğduğundan söz edebiliriz. Küçük firmaların platformlar aracılığıyla yerel piyasaların dışına çıkıp dünyaya seslerini duyurmaları olanaklı hale gelmiştir. Bütün bu gelişmelere karşın dünya ticaretine damgasını vuran global değer zincirleri ve bu zincirleri biçimlendiren dev ulus aşırı şirketlerdir. 
Erkök Yılmaz, Ş. (2021). Firmalar ve dünya ekonomisi.

Fiscaoeconomia, 5(2), 372-389. doi: 10.25295/fsecon.916030

\section{Global Değer Zincirleri ve Bölgeler Arası Yakınsama?}

Global Değer Zincirlerinin belirlediği ticaret toplam dünya ticaretinin \%80'ini oluşturmakta ve büyük firmaların \%15'i arasında yapılmaktadır (WBG-WDR, 2020:16). Küresel değer zincirlerini geleneksel ticaretten ayıran iki temel özellik vardır: 1) Aşırı uzmanlaşma, 2) firmalar arası sağlam ilişkiler. Olaya bu açıdan yaklaştığımızda üçülke ve bu ülkelerdeki firmaların kurdukları üretim ağları ile oluşturdukları üç coğrafi bölge üretim ve ticaret ilişkilerinin yoğunlaştığı bölgeler olarak belirmektedir. Merkez ABD olmak üzere Kuzey Amerika, merkez Almanya olmak üzere Orta ve Doğu Avrupa ve merkez Çin olmak üzere Güney Doğu Asya. Bu bölgelerden Kuzey Amerika sağlık, biyo teknoloji ve elektronik alanında yoğun ticari ilişki içindeki firmaların yer aldığı alan olarak göze çarpmaktadır. Çin de ABD örneğini benimsemiş görünmekte ve ağırlıklı olarak biyo-teknoloji ve bilişim teknolojilerinde yoğunlaşmış üretim ve ticari ilişkiler ağına sahiptir. Buna karşılık Almanya'da ön plana çıkan sektörler otomotiv başta olmak üzere ecza ve sağlıktır (WIPO-WIPR, 2017:24).

Sermayenin liberalizasyonuna bağlı olarak uluslararası hale gelen üretim yapısı dünya ekonomisine yeni ülkelerin eklemlenmesine yol açmıştır. Dünya pazarlarına açılan bu yeni ülkelerde belli bir gelir artışı ve bu artışa bağlı olarak bölgeler arası bir yakınsama eğiliminden söz etmek mümkündür. Ancak dünya ekonomisine eklemlenenler arasında gelişmiş ülkelerle rekabet edebilecek güce erişen ülke sayısı azdır ve bu az sayıda ülke başarısını neo-liberal politikalara değil, bu politikalardan olabildiğince sakınmalarına borçludur. Doğu Asya örneğinde ülkelerin gelişmişlik durumuna bakacak olursak Japonya kalkınma sürecine çok önceden başlamış, ekonomisinin zorla dışa açtırımasına karşın kendine özgü bir kalkınma stratejisi izleyerek yarı-sömürge olmaktan kısa süre içinde sıyrılmış ve gelişmiş ülkeler arasında yerini almıştır. Güney Kore de benzer bir biçimde tamamen doğrudan yabancı sermaye girişlerinin yönlendirdiği bir ekonomi olmamış, tersine, gelen yabancı sermayeyi kendi belirlediği stratejik hedefler doğrultusunda çalıştırmayı başarmış, yatırımlara verdiği teşviklerde seçici ve gerektiğinde cezalandırıcı olabilmiştir. Doğu Asya'daki bu başarılı örnekler kuşkusuz Çin için de ders niteliğindeydi. Bugün $A B D$ ve $A B^{\prime}$ nin gelişmiş ülkeleriyle yarışabilen Çin, bir yandan yabancı sermaye için cazip odaklar yaratırken (serbest bölge uygulamaları gibi), neo-liberal akıntının kendisini sürüklemesine izin vermeyerek sermaye girişleri ve döviz üzerindeki denetimlerini sürdürmüş ve her şeyden önemlisi gelen yabancı sermayeden gerekli teknolojiyi öğrenme ve geliştirme yolunda bilinçli politikalar izlemiştir. 1988 yılında başlattığı El Feneri (Torch) Programı başlığı altında ülkesindeki üniversiteler, araştırma enstitüleri ve işletmeleri bir araya getirerek teknolojik potansiyeli artırmak, yüksek teknoloji ürünleri üretmek ve yeni sektörlere açılmak için Yüksek-Endüstriyel Kalkınma Bölgeleri (HIDZ) oluşturmuş, yabancı şirketlerin bu alana katkılarını da sağlayarak AR-GE çalışmalarının ticarileşmesine ön ayak olmuştur (Kozul-Wright,2018:11). Çin'in kırsal kesimdeki yoğun köylü nüfusu kentlere göçe zorlayarak ucuz işgücünü bir rekabet avantajı olarak kullandığı da bilinmektedir. Aynı şey Hindistan için de olası iken Hindistan iç göçlerden yeterince yararlanamamış, bu da ülke içindeki bölgesel eşitsizlikleri tırmandırmıştır. Ancak Hindistan'ın önceki dönemlerden getirdiği planlama alışkanlığını sürdürerek neo-liberal politikalara tam bir teslimiyet içinde olmadığı görülmektedir. Buna karşılık Malezya tüketim-önderliğinde bir kalkınma modeli benimsemesinin cezasını ekonomik krizlerle ödemiştir. 
Erkök Yılmaz, Ş. (2021). Firmalar ve dünya ekonomisi.

Fiscaoeconomia, 5(2), 372-389. doi: 10.25295/fsecon.916030

\section{Kamunun Yeniden Artan Önemi}

Liberalleşme ve özelleştirme furyası politik söylem olarak sürüp giderken, geçtiğimiz son 30 yılda devletin ekonomideki öneminin arttığını görmekteyiz. 2008 küresel krizi uluslararası yatırım yapanlar arasına yeni tür yatırımcıların katılmasına yol açmıştır. Bu yeni tür yatırımcılar Varlık Fonları, Devlet İşletmeleri ve özel varlık fonlarıdır. Küresel ölçekte iş yapan belli başlı varlık fonlarının sayısı 100'e yaklaşmıştır. Varlık fonlarının yönetimindeki fonların tutarı 2012 yılında 5.3 trilyon doları geçmiş bulunuyordu ve bu aktiflerin \%80'i gelişmekte olan ülkelerin elindeydi. Varlık fonları eliyle gerçekleştirilen doğrudan yatırımlar her yıl katlanarak artmaktadır. Ancak varlık fonlarının doğrudan yatırımlardan çok şirket birleşme ve satın almaları tercih ettikleri görülmektedir. Doğrudan yatırımlarını genellikle hizmet sektörüne (\%70) yöneltmekte, finansman, konut, inşaat ve elektrik, su, doğal gaz gibi temel ihtiyaç alanlarını seçmektedirler (UNCTAD-WIR,2013:11).

$\mathrm{Bu}$ anılan yeni tür yatırımcıların yanı sıra devlet mülkiyetinde ulus aşırı şirketlerin (Kamusal Ulus Aşırı Şirket-KUAŞ) kurulduğunu da görmekteyiz. Bu şirketler dünyanın en büyük 100 şirketi arasında yer almayı başarmıştır. 2018 yılı için bu sayı en büyük 100 şirket içinde $16^{\prime}$ dır. Devlet mülkiyetindeki ulus aşırı şirketler tercihlerini doğrudan yatırım yapmaktan yana kullanmaktadır öyle ki ülke dışına çıkan yabancı sermaye yatırımlarının 1/10'u bu şirketlere aittir. 2018 yılı itibariyle sayıları 1500'ü bulan Kamusal Ulus Aşırı Şirketin 1/3'ü Avrupa ülkelerine, $\% 45$ 'i gelişmekte olan Asya ülkelerine aittir. Asya ülkelerindeki KUAŞ'ların \%18'i Çin kökenlidir; Çin şirketlerinin 5'i en büyük 100 şirket arasında yer almaktadır (UNCTAD-WIR, 2019:6).

Son yıllarda ülkelerin kalkınmasına yön veren büyük firmalardır. AR-GE çalışmalarının meyvelerini deren ve AR-GE'yi ticarileştiren de büyük firmalardır. Firmalar kendi iç dinamikleriyle büyüyebilir veya büyümeye fırsat bulamadan piyasadan çekilmek zorunda kalabilirler. Gelişmekte olan ülkelerin gelişmiş ülkeleri yakalamaları için büyük firmalara gereksinimleri vardır. Ancak bu süreci doğal akışına bırakacak zamanları ve lüksleri de bulunmamaktadır. Devlete bu noktada kritik bir görev düşmektedir: Stratejik alanlarda devlet eliyle büyük şirketler kurmak. Örneğin Çin'deki 150 büyük şirketin en büyük hissedarı kamudur. Borsadaki değerin \%80'ini kamu şirketleri oluşturmaktadır. Aynı oran Rusya Federasyonu'nda \%62, Brezilya'da \%38'dir (UNCTAD-WIR,2013:12). Bugün devlet eliyle kurulan Çin şirketleri en yüksek AR-GE harcaması yapan şirketler arasında sayıları ve AR-GE yoğunlukları ile dikkat çekmekte ve belki de Çin mucizesinin temelini bu şirketler oluşturmaktadır. Bu doğrultuda gene bir diğer Çin başarısı devlet eliyle kurulmuş kalkınma bankaları ile gene devletin ortak olduğu kalkınmayı finanse eden kurumlardır. Çin zengin ülkelerin önde giden sektörlerini kendi ülkesinde kurmayı ve bu sektörler için gerekli teknolojik ve toplumsal yapabilirlikleri geliştirip ilerletmeyi başarmıştır. Hızlı yatırım artışlarına öğrenme ve ölçek ekonomileri eşlik etmiş ve sürdürülebilir verimlilik artışları sağlanabilmiştir (UNCTADTDR, 2018:45). Çin'de yirmi yıl içinde sayıları 400'leri bulan UAŞ'ler 2015 yılında en tepedeki UAŞ kârlarının \%17'sine sahip olmuşlardır (UNCTAD-TDR, 2018:58).

Çin'in bu deneyimleri Türk okurları için yabancı değildir. Daha 1930'larda Cumhuriyet hükümetleri İktisadi Devlet Teşebbüsleri ile bu modeli başlatmış ancak değişen siyasal tercihler sonucu IDT'ler amacından uzaklaşarak ekonomi için iddia edildiği gibi bir yük haline getirilmiş ve birer ikişer yok pahasına özelleştirilmişlerdir. Keza AR-GE çalışmalarının merkezi olarak 
Erkök Yılmaz, Ş. (2021). Firmalar ve dünya ekonomisi.

Fiscaoeconomia, 5(2), 372-389. doi: 10.25295/fsecon.916030

düşünülen TUBITAK daha iyi, daha gelişmiş bir kurum haline dönüştürülebilecekken 2018'den bu yana Sanayi Teknoloji Bakanlığının bir alt kuruluşu haline getirilmiş ve TUBiTAK bursları Sanayi Teknoloji Bakanlığı, KOSGEB gibi kuruluşlar aracılığıyla ağırlıklı olarak KOBi'lere dağıtılmıştır. KOBi'lerin bu finansal yardımlarla kısa vadeli finansman ihtiyaçlarını karşılamak dışında AR-GE'ye yönelik atılımlar yaptıklarını ileri sürmek pek mümkün görünmemektedir (ayrıntılı bilgi için bk.Erkök Yılmaz, 2019:98).

\section{AR-GE Yatırımları ve Türkiye}

AR-GE çalışmaları kuşkusuz büyük firmaların tekelinde olmamalıdır ancak AR-GE'nin hayata geçirilmesi aşamasında finansman ve işletmecilik, pazarlama deneyimleri ön plana çıkmaktadır. İşte bu aşamada şanslı olan büyük firmalardır. Büyüklük kadar firma deneyimi, firmanın geçmişten bu güne çalıştığı alan başarı için vaz geçilmez bir önkoşuldur. Kurumların geçmişi onların gelecekteki başarımlarının garantisidir. Bu açıdan olaya yaklaştığımızda kurumsal geçmişi olan işletmelerin politik tercihler sonucu kapatılması, yenilerin işi öğrenene kadar mevcut fırsatları zamanında değerlendirememesi zaman kaybından başka bir şey değildir. Ayrıca yeni yatırım yapmak ve yenilik arayışı içinde olmak için ekonomik istikrar ve başarının ödüllendirilmesine gereksinim vardır. Uygun bir yatırım ortamı yoksa mevcut kurumların başarımında yükselme beklemek hayal olur. Nitekim Türkiye genelinde 2000 'den bu yana AR-GE harcamaları itibariyle ilk 2500 firma içinde yer alan firma sayısı 2'den 2019 yılı itibariyle 5'e çıkmıştır (TABLO:1). Bu firmalardan dördü özel sektör firmasıdır ve otomotiv yan sanayisi ile dayanıklı tüketim malları sanayisinde çalışmaktadırlar. Satış hasılatları itibariyle birbirine yakın olup aynı sektörde iş yapan yabancı firmalarla karşılaştırıldığında bu firmaların AR-GE yoğunluklarının düşük olduğunu söylemek yanlış olmaz. (TABLO: 2, 3, 4, 5, 6) Devlet destekli olup elektronik alanında çalışan firma ise satış hasılatı itibariyle kendisine benzer yabancı firmalarla karşılaştırıldığında AR-GE yoğunluğu itibariyle çok düşük görünmese de küresel AR-GE yoğunluğunun ortalama \%7 dolayında olduğu elektronik sektörü özelinde değerlendirildiğinde oldukça düşük bir yoğunluk sergilemektedir.

Tablo 1: En Fazla AR-GE Yatırımı yapan 2500 Firma ve Ülkeleri

$2008 \quad 2018$

\begin{tabular}{lcc} 
Ülkeler & Firma Sayısı & Firma Sayısı \\
\hline Çin & 15 & 507 \\
Hindistan & 15 & 32 \\
İsrail & 7 & 22 \\
Japonya & 256 & 318 \\
G. Kore & 22 & 70 \\
İsviçre & 38 & 59 \\
Tayvan & 41 & 89 \\
ABD & 531 & 768 \\
Avustralya & 8 & 12 \\
Türkiye & 2 & 5
\end{tabular}

Kaynak: JRC-EC, 2009 ve 2019 
Erkök Yılmaz, Ş. (2021). Firmalar ve dünya ekonomisi.

Fiscaoeconomia, 5(2), 372-389. doi: 10.25295/fsecon.916030

Tablo 2: Otomotiv Sektörü Firmalar Arası Karşılaştırma (TOFAŞ örneği)

\begin{tabular}{llccc} 
Firmalar & Ülkeler & $\begin{array}{c}\text { Satış Geliri } \\
\text { (mil.€) }\end{array}$ & $\begin{array}{c}\text { AR-GE } \\
\text { (mil.€) }\end{array}$ & $\begin{array}{c}\text { AR-GE } \\
\text { Yoğunluğu \% }\end{array}$ \\
\hline Toyo Tire & Japonya & 3098,7 & 85.7 & 2.8 \\
Cheng Shin & Tayvan & 3103,8 & 151.4 & 4.9 \\
TOFAŞ & Türkiye & 3167,8 & 41.4 & 1.3 \\
Cooper Standard & ABD & 3169,7 & 107.0 & 3.4
\end{tabular}

Kaynak: JRC-EC, 2019

Tablo 3: Otomotiv Sektörü Firmalar Arası Karşılaştırma (FORD OTOMOTiV Örneği)

\begin{tabular}{llccc} 
Firmalar & Ülkeler & $\begin{array}{c}\text { Satış Geliri } \\
\text { (mil.€) }\end{array}$ & $\begin{array}{c}\text { AR-GE } \\
\text { (mil.€) }\end{array}$ & $\begin{array}{c}\text { AR-GE } \\
\text { Yoğunluğu \% }\end{array}$ \\
\hline Hankook Tire & G. Kore & 5319,1 & 128.1 & 2.4 \\
NHK Spring & Japonya & 5366,5 & 132.6 & 2.5 \\
Ford Otomotiv & Türkiye & 5521,8 & 93.9 & 1.7 \\
VDL Groep & Hollanda & 5856,2 & 122.0 & 2.1
\end{tabular}

Kaynak: JRC-EC, 2019

Tablo 4: Elektronik Sektörü Firmalar Arası Karşılaştırma (ASELSAN Örneği)

\begin{tabular}{llccc} 
Firmalar & Ülkeler & $\begin{array}{c}\text { Satış Geliri } \\
\text { (mil.€) }\end{array}$ & $\begin{array}{c}\text { AR-GE } \\
\text { (mil.€) }\end{array}$ & $\begin{array}{c}\text { AR-GE } \\
\text { Yoğunluğu \% }\end{array}$ \\
\hline Siltronic & Almanya & 1456,7 & 67.6 & 4.6 \\
ASELSAN & Türkiye & 1494,2 & 71.9 & 4.8 \\
NKT & Danimarka & 1501,6 & 81.2 & 5.4 \\
Hyundai Electronic & G. Kore & 1518,9 & 32.8 & 2.2
\end{tabular}

Kaynak: JRC-EC, 2019

Tablo 5: Genel Endüstri Firmalar Arası Karşılaştırma (KOÇ örneği)

\begin{tabular}{llclc} 
Firmalar & Ülkeler & $\begin{array}{c}\text { Satış Geliri } \\
\text { (mil.€) }\end{array}$ & $\begin{array}{c}\text { AR-GE } \\
\text { (mil.€) }\end{array}$ & $\begin{array}{c}\text { AR-GE } \\
\text { Yoğunluğu \% }\end{array}$ \\
\hline KOÇ & Türkiye & 26771,5 & 66.3 & 0.2 \\
Johnson Controls & İrlanda & 27423,6 & 331.9 & 1.2 \\
3M & ABD & 28615,7 & 1090,0 & 3.8 \\
Toshiba & Japonya & 29105,8 & 1319,8 & 4.5
\end{tabular}

Kaynak:JRC-EC, 2019 
Erkök Yılmaz, Ş. (2021). Firmalar ve dünya ekonomisi.

Fiscaoeconomia, 5(2), 372-389. doi: 10.25295/fsecon.916030

Tablo 6: Ev Aletleri Sektörü Firmalar Arası Karşılaştırma (ARÇELiK Örneği)

\begin{tabular}{llccc} 
Firmalar & Ülkeler & $\begin{array}{c}\text { Satış Geliri } \\
\text { (milyon } € \text { ) }\end{array}$ & $\begin{array}{c}\text { AR-GE } \\
\text { (milyon } € \text { ) }\end{array}$ & $\begin{array}{c}\text { AR-GE } \\
\text { Yoğunluğu \% }\end{array}$ \\
\hline Osram Licht & Almanya & 4115,0 & 428.0 & 10.4 \\
Hisense Home & Çin & 4139,3 & 128,5 & 3.1 \\
ARÇELiK & Türkiye & 4462,4 & 54.7 & 1.2 \\
Fortune Brands & ABD & 4790,5 & 43.9 & 0.9
\end{tabular}

Kaynak: JRC-IRI, 2019

\section{Ne Yapmalı?}

Dijital ekonomide kalkınma atılımları yapmanın yolu her şeyden önce bilgisayar ve yazılım için gerekli alt yapıyı oluşturmaktan geçmektedir. Dijital alt yapı kadar dijital becerileri de geliştirmek gerekmektedir. Internet kullanımı gelişmiş ülkelerde $\% 97$ düzeyinde iken gelişmekte olan ülkelerde bu oran \%48, Afrika'da \%22'dir (UNCTAD- TDR, 2018: vii). Değer zincirlerinin yüksek katma değerli halkalarında üretim öncesi ve sonrası yer almak da bu alt yapıya sahip olmaktan geçmektedir. Dijital platformları düzenlemek ve ulusal pazarlama platformları oluşturmak özellikle e-ticaretten yararlanmak açısından son derece önemlidir. Ulusal veri politikası şu dört soruna göre tasarlanmak zorundadır: veriler kimin mülkiyetinde olabilir; nasıl toplanabilir, kim kullanabilir ve hangi koşullar altında kullanabilir. Hangi veriler egemenlik haklarıyla ilgilidir, yani hangi veriler ülke dışına çıkarılabilir ve ülke yasalarının koruması altında değildir (UNCTAD-TDR, 2018: vii) gibi sorulara açıklık getirilmesi gereklidir. Yaşadığımız çağ bilişim teknolojisinin CAD (bilgisayar destekli tasarım), CAM (bilgisayar destekli üretim) gibi aşamaları geride bırakıp CEM (bilgisayarla bütünleşmiş üretim) aşamasına geçtiği bir çağdır. Bu çağda örneğin 3 Boyut teknolojisi ve robotların yaygın kullanımı üretim ilişkilerinin yeni baştan kurgulanmasını ve dünya üretim örüntüsünün tamamen değişmesini, küreselleşmenin yerelleşmeye evrilmesini bile gündeme getirebilir. Önemli olan bu gelişmeleri kavrayacak ve ileriye taşıyacak beşeri sermayeyi ülke genelinde hazır bulundurmaktır. Bu da ancak bilinçli siyasal kadroların önderliğinde, gerekirse devlet desteğiyle kurdurulacak büyük firmaların yeni teknolojik fırsatlardan yararlanmalarını sağlamakla mümkündür.

\section{Kaynakça}

Baldwin, R., (2012), "Global Supply Chains: Why they emerged, Why they matter and Where they are going" Fung Global Institute, WP, FGI-2012-1, www.fungglobalinstitute.org

Brynjolfsson, E., A. McAfee, M.Sorell, F. Zhu (2012), "Scale Without Mass: Business Process Replication and Industry Dynamics", http//:ssrn.com

Coase, R. H., (1937), "The Nature of Firm", Economica 4 (16):386-405.

Dunning, J., (1995), "Reappraising the Eclectic Paradigm in the Age of Allied Capitalism", Journal of International Business Studies, Vol.26(3).

Dunning, J., (1998), "Location and the Multinational Enterprise: a neglected factor" Journal of International Business Studies, Vol.29 (1). 
Erkök Yılmaz, Ş., (2019), “AR-GE Destekleri ve KOBi'ler”, iktisat ve Toplum, Yıl:9, Sayı:104:8999

Hymer, S. H.,(1968), "The Multinational Corporation and the Law of Uneven Development", Economics and World Order, J. N. Bhagwati, McMillan Company, 1972

Gereffi, G., O. Memedovic, (2003), "The Global Apparel Value Chain: What Prospects for Upgrading by Developing Countries", UNIDO Strategic Research and Economics Branch, Vienna, Austria.

Kaczmarczyk,P. (2020), "Growth Models and the Footprint of Transnational Capital”, MaxPo, Discussion Paper No.20/2 www.ECONSTORE.EU

Kozul-Wright, R., D. Poon, (2018), "Asian Development after the Asian Drama”, WIDER WP, No.135, www.ECONSTORE.EU

Laperche, B., G. Lefebvre, (2012), "The Globalization of Research \&AMP; Development in Industrial Corporations: Towards 'Reverse Innovation'? The Cases of GE and Renault", Journal of Innovation Economics \& Management, 2:53-79, www.cairn.info

JRC-EC, (2009),Monitoring Industrial Research: The 2009 EU Industrial R\&D Investment Scoreboard, www.jrc.ec.europa.eu

JRC-EC, (2019), EU R\&D Scoreboard: The 2019 Industrial R\&D Investment Scoreboard, www.jrc.ec.europa.eu

UNCTAD, (2005), World Investment Report (WIR): Transnational Corporations and the Internalization of $R \& D$ https://unctad.org

UNCTAD,(2013), World Investment Report (WIR): Global Value Chains: Investment and Trade for Development https://unctad.org

UNCTAD, (2018), Trade and Development Report (TDR) : Power, Platforms \& Free Trade Delusion, https://unctad.org

Wallerstein, I., (1982), "World Systems Analysis:Theoretical and Interpretative Issues", World Systems Analysis, Terence K. Hopkins, I. Wallerstein, vd., Sage Publications, USA.

WB Group (2019), World Development Report (WDR): The Changing Nature of Work www.worldbank.org

WB Group, (2020), World Development Report (WDR): Trading for Development in the Age of Global Value Chains, WBG Flagship Report www.worldbank.org

WIPO, (2017), World Intellectual Property Report (WIPR): Intangible Capital in Global Value Chains, www.wipo.int

Zingales, L. (2017), "Towards a Political Theory of Firms", Journal of Economic Perspectives, Vol.31, No.3, Summer:113-130. 
Erkök Yılmaz, Ş. (2021). Firmalar ve dünya ekonomisi.

Fiscaoeconomia, 5(2), 372-389. doi: 10.25295/fsecon.916030

Etik Beyanı: Bu çalışmanın tüm hazırlanma süreçlerinde etik kurallara uyulduğunu yazar beyan eder. Aksi bir durumun tespiti halinde Fiscaoeconomia Dergisinin hiçbir sorumluluğu olmayıp, tüm sorumluluk çalışmanın yazarına aittir.

Ethics Statement: The author declares that ethical rules are followed in all preparation processes of this study. In case of detection of a contrary situation, Fiscaoeconomia has no responsibility and all responsibility belongs to the author of the study. 
Erkök Yılmaz, Ş. (2021). Firmalar ve dünya ekonomisi.

Fiscaoeconomia, 5(2), 372-389. doi: 10.25295/fsecon.916030

\section{Firms and the World Economy}

\section{Şiir ERKÖK YILMAZ}

\section{Extended Abstract}

Ronald Coase in 1930s observed that firms grew only so long as it was cheaper for them to complete additional parts of the production process in-house. Along with this internalization process growing firms suffered by huge coordination costs. Hymer in 1960 s pointed out that the internationalization of production process can be an alternative strategy for the large firms to refrain from the costs of internalization. However, internationalization of production was also subject to trade barriers and transportation costs. From 1980 onwards trade and financial liberalization accompanied by radical technological developments in transportation, information and communication (IC) have reduced the cost of cross-border trade so that internationalization of production became much cheaper than internalization. As a result, firms are less vertically integrated today and the managers prefer outsourcing more jobs than producing them at home. Firms through global value chains (GVC) unbundled their production processes thus changed the geography of jobs and traditional trade patterns. Nowadays large firms named Transnational Corporations (TNC) or superstar firms dominate the international production through global value chains. The decision-making procedure of TNCs affects the restructuring of the global economy. The aim and organization of these chains also determine the hierarchy among the firms. Firms' market power is the outcome of their intangibles assets. These intangible assets consist of patents, royalties, copyrights, design, software, market analysis and data and they specifically belong to the leader firm in GVC. These assets are not easily obtained but derive huge profits for their owners. In order to catch and sustain a competitive advantage firms ought to increase these intangible assets through R\&D investments. Recent decades are called as hyper globalization era and the characteristic feature of this era is the hyper competition among large firms through innovation. Larger firms are luckier to carry on R\&D activities and to evaluate and commercialize any kind of invention or innovation wherever it has been developed. Firms that successfully diffuse innovations grow faster at the expense of other firms hence a greater concentration takes place even under hyper competition rules. The monopolistic power of the leading firm does not last too long because competitors and new entrants can easily replicate the new product or practices with the help of Information Technology. ICT technologies has enabled the firms to grow faster than they did twenty years ago but these larger firms cannot be assured about their market dominance because of the higher levels of uncertainty and rivalry. Schumpeterian Creative Destruction is working at global level bringing new entrants and new products to the market.

Digital technologies allow firms to scale up and down quickly blurring the traditional boundaries of the firms. New business models such as digital platform firms are evolving from local start-ups to global giants, often with few employees or tangible assets. Digital Platforms operate in adjacent and multisided markets bundling different types of services and expand into other business lines so that the distinction between manufacture and service sectors disappear. Firms or individuals need only a broadband connection to trade goods and services through the platforms. Millions of people- consumers, suppliers, entrepreneurs, investors, inventors, financing agents, employees etc.- who do not live in the same country or region or 
Erkök Yılmaz, Ş. (2021). Firmalar ve dünya ekonomisi.

Fiscaoeconomia, 5(2), 372-389. doi: 10.25295/fsecon.916030

on the same continent are able to get in touch and to exchange their goods, services, ideas, skill, labour capital on these platforms. The digital platforms provide services free of charge in exchange for user data on one side of the market and financialize the same data on some other side of the same market. Data, like ideas and knowledge, can be used for various purposes and turn into an intangible asset that raises firm's efficiency and competitive advantage.

GVC trade and facilities that ICT bring to the emerging countries helped them to join in international production and to attain higher rates of growth but it is hard to mention about a convergence between the developing and the developed economies. Only the countries which succeeded in transferring the core R\&D activities to their territories and upgrading the production processes under their responsibility are ranked among the top economies that monitor the global economy. Since technological developments are carried on by the large firms, government support for the R\&D should be directed to the firms which show high R\&D intensity. TABLE 1 indicates China's success in this respect. Among the top 2500 R\&D investors the number of Chinese firms increased from 12 in 2008 to 500 in 2019. During the same period the number of Turkish R\&D investor firms increased from 2 in 2008 to 5 in 2019 and these firms work in the mature industries that are quite stagnant in technological sense. Table $2,3,4,5$, and 6 aim to compare the R\&D intensities of these five firms with the foreign firms that work in the same industry and approximately have the same net sales revenue. The picture is quite disappointing for Turkish firms. TABLEs indicate that Turkish firms with low $R \& D$ intensities are far from catching their global rivals and with these poor R\&D performances cannot escalate the upper stages of international production. Turkey has failed to orient the large domestic firms towards promising technological fields of the digitalized world. The political choice of the governments to financially support small manufacturing enterprises instead of larger firms and the absurd high education schooling policy pursued by the governments are the main reasons for this failure. The financial and institutional instability that Turkish economy suffered in recent decades created an unfavourable environment for the investors as well. Struggling for a decisive and inclusive research and innovation policy is compulsory for the political authorities to rescue future generations from unemployment and poverty.

Despite the neoliberal recipes designed for the emerging economies, state intervention is frequently taken place in the developed South (especially in China) where State Owned Enterprises and Sovereign Wealth Funds emerged as new kind of investing corporations. Especially Chinese State-Owned Enterprises ranked among the world's top R\&D investors. And the success of these enterprises implies that the late comers' advantage is not a dream. In emerging economies governments should adopt a strategic policy to urge the firms engage in digital economy. The first step in this direction is to provide hard and soft digital infrastructure for the requirements of consumers and enterprises. Digital capabilities are also as important as the digital infrastructure and they can only be raised by lifelong education. Human capital is the key driver to enjoy the opportunities brought by the digital technology. To ease and regulate the establishment of digital platforms is also vital for the developing countries to join in e-commerce. To design and implement a national data policy is also necessary for the expansion of digital platforms. Governments should give financial support to the firms which are rich in human capital and are able to undertake R\&D operations. Recent developments in 


\section{FSECON}

Erkök Yılmaz, Ş. (2021). Firmalar ve dünya ekonomisi.

Fiscaoeconomia, 5(2), 372-389. doi: 10.25295/fsecon.916030

computer-integrated manufacturing can be learned and absorbed only by the firms that are able to evaluate and to respond to the surprising attacks of digital technology. 